\title{
COST 296 MIERS: Mitigation of Ionospheric Effects on Radio Systems
}

\author{
Alain Bourdillon $\left({ }^{1}\right)$, Ljiljana R. Cander $\left({ }^{2}\right)$ and Bruno Zolesi $\left({ }^{3}\right)$ \\ $\left(^{1}\right)$ IETR, Université de Rennes 1, France \\ $\left(^{2}\right)$ STFC, Rutherford Appleton Laboratory, Chilton, UK \\ $\left(^{3}\right)$ Istituto Nazionale di Geofisica e Vulcanologia, Roma, Italy
}

\begin{abstract}
The COST 296 Action MIERS (Mitigation of Ionospheric Effects on Radio Systems) within the ionospheric community has the objectives, embodied in the Memorandum of Understanding (MoU), to develop an increased knowledge of the effects imposed by the ionosphere on practical radio systems, and the development and implementation of techniques to mitigate the deleterious effects of the ionosphere on such systems. This introductory paper summarizes briefly the background and historical context of COST 296 and outlines the main objectives, working methods and structure. It also lists the participating countries and institutions, the Management Committee (MC) Meetings, the Workshops, Short-term Scientific Missions. In addition, the paper discusses the dissemination activities and the collaboration among the participating institutions and researchers, before outlining the content of the Final Report.
\end{abstract}

Key words Ionospheric physics and propagation COST action

\section{Background and historical context}

Temporal and spatial changes in the upper atmosphere act to limit and degrade the performance of terrestrial and Earth-space radio systems in many different ways. Command, control and communication systems involving transionospheric propagation may be disrupted or strongly perturbed, global positioning networks compromised and surveillance (optical and radar) systems affected. In addition, conditions in nearEarth space have other adverse effects on modern technology, ranging from the tracking and

Mailing address: Dr. Alain Bourdillon, IETR, Université de Rennes, 1 UMR CNRS 6164, 35042 Rennes, France; e-mail: alain.bourdillon@univ-rennes1.fr the lifetimes of satellites to the induction of strong damaging currents in the power grids and transcontinental pipelines. The vulnerabilities of systems to changes in the upper atmosphere incorporate many different aspects like spaceweather effects on communication, navigation and surveillance systems, solar cycle phenomena and their impact on operational systems; modeling, forecasting, and prediction services; ionospheric sounding methods and measurements; applications of ionospheric tomography; transionospheric effects including scintillation; ionospheric propagation for high frequency communication systems; long wave propagation systems and effects; very low frequency propagation for long-range communication with receiver below sea surface; Global Positioning System (GPS) and ionospheric Total Electron Content (TEC) studies. The European ionospheric community has long been aware that cooperation research on an international basis is essential to deal with such complex issues. In par- 
ticular, international cooperation is required for the collection of data, in both the real-time and in retrospective modes, the development and verification of new methods to improve the performance of both operational and future terrestrial and Earth-space communication systems and the exchange of expertise on space plasma effects on Global Navigation Satellite Systems (GNSS).

COST is a European Cooperation in the Field of Scientific and Technical Research. It is a framework for scientific and technical cooperation, allowing the coordination of national research on a European level for basic and pre competitive research as well as activities of public utility. It is an intergovernmental mechanism that sponsors scientific and technical co-operation and co-ordination between research team and institutional partners from the COST countries and non COST institutions. COST 296 MIERS on «Mitigation of Ionospheric Effects on Radio Systems» is an Action within the ICT «Information and Communication Technologies» domain. The area is managed in the COST Office, in close liaison with the 6th FP IST program. It is a four-year project that started in January 2005 to work collaboratively on the topics outlined above. The core of COST 296 has been a dynamic group of researchers from 19 COST countries and 7 institutions from non COST countries and the European Space Agency (ESA) working as a technical community towards a common objective. COST projects are well suited to developing research co-operation in fields where finance is provided at the national level. The success of this approach has been demonstrated in the telecommunications domain in previous COST Actions concerned with the prediction of ionospheric propagation characteristics (Zolesi and Cander, 2008).

The earlier COST Actions relating to ionospheric radio propagation were particularly useful in creating a critical mass of researchers in projects where the initial emphasis was on long-term ionospheric prediction and retrospective ionospheric modeling over Europe. The COST 238 Action PRIME (Prediction and Retrospective Ionospheric Modeling over Europe) was a four-year research project with objectives to develop regional maps and models over the European ionosphere that are more accurate than internationally available global maps and models (Bradley, 1995). It involved the participation of some 72 scientists and engineers from 17 countries. The work encompassed the production of regional monthly median maps and algorithms for generating «instantaneous» snapshot maps of the standard vertical-incidence ionospheric characteristics from coordinated sounding measurements within Europe. Additional studies involved height profiles of electron density, the vertical total electron content up to an altitude of $1000 \mathrm{~km}$ and research leading to an improved understanding and thus potential for better modeling of ionospheric storm morphologies. Work conducted within COST 238 was continued in the follow-on project COST 251 IITS (Improved quality of service in Ionospheric Telecommunication Systems planning and Operation) on the application of PRIME results in the improved quality of service in ionospheric telecommunication systems planning and operation (Hanbaba, 1999).

Both projects yielded significant results, but they also identified further areas where future development was needed. The topics for more research included: hour-to-hour and day-to-day variability prediction capabilities in the topside ionosphere, upgrading of the current models to include scintillation effects, the prediction of the ionospheric and plasmaspheric effects on navigational systems and the development of methods for calculating the reliability and compatibility of HF radio systems using digital modulation techniques and over the horizon HF backscatter radars.

The COST 271 Action «Effects of the upper atmosphere on terrestrial and Earth-space communications» was then established to examine a range of relevant research areas within four broad groupings:

- Impact of variability of space environment on communications

- Assessment of space plasma effects for satellite applications

- Ionospheric effects on terrestrial communications

- Space plasma effects on Earth-space and satellite-to-satellite communications

The major achievements of COST 271 are described in Zolesi and Cander (2004). 


\section{COST 296 action objectives}

COST 296 is an Action for the promotion, stimulation and co-ordination of European research in ionospheric areas.

The Memorandum of Understanding laid out the main objectives of the COST 296 Action as follows:

- To support and enhance the existing European facilities for historical and real-time ionospheric data collection accessible to all;

- To exchange information on methods and algorithms to mitigate the effects of ionospheric perturbations and variations on advanced terrestrial and space-based communication services by creating an effective computing infrastructure;

- To develop an integrated approach to ionospheric modeling;

- To create the mechanism needed to ingest measured parameters into models, extend and develop suitable mitigation models and define the protocols needed to link models together;

- To make applicable results available to the ITU-R and to promote the research aspects to funding agencies such as ESA, ESF and the EU;

- To elaborate inputs for the preparation of the future European Space Programme (ESP);

- To strengthen the existing areas of expertise by stimulating closer cooperation between scientists and users;
- To focus the scope of all the previous COST ionospheric related studies to the mitigation of ionospheric effects on specific radio systems.

\section{COST 296 action working method and structure}

The action was organized under three topic headings corresponding to three working groups and associated ten work packages as shown in table I as well their term of references.

Members of the Management Committee of the Signatory Countries, participating institutions from COST and non-COST countries and MC meetings, Workshops and Short-term Scientific Mission are listed below.

\subsection{Working Group 1 - Ionospheric monitor- ing and modelling}

- Near-Earth space plasma monitoring by vertical incidence and oblique sounding networks and GNSS techniques (retrospective and real-time).

- Data ingestion and assimilation into ionospheric models, including data collection and processing, and the adaptation of models to enable data ingestion and assimilation.

Table I. COST 296 action structure

\begin{tabular}{|c|c|c|}
\hline $\begin{array}{l}\text { WG1 - Ionospheric monitoring } \\
\text { and modelling }\end{array}$ & $\begin{array}{c}\text { WG } 2 \text { - Advanced terrestrial } \\
\text { systems }\end{array}$ & $\begin{array}{l}\text { WG } 3 \text { - Space-based } \\
\text { systems }\end{array}$ \\
\hline $\begin{array}{l}\text { WP } 1.1 \text { - Near Earth space } \\
\text { plasma monitoring }\end{array}$ & $\begin{array}{l}\text { WP } 2.1 \text { - Radar and } \\
\text { radiolocation }\end{array}$ & $\begin{array}{c}\text { WP } 3.1 \text { - Space plasma } \\
\text { effects }\end{array}$ \\
\hline $\begin{array}{l}\text { WP } 1.2 \text { - Data ingestion and } \\
\text { assimilation in ionospheric models }\end{array}$ & $\begin{array}{l}\text { WP } 2.2-\mathrm{HF} / \mathrm{MF} \\
\text { communications }\end{array}$ & WP 3.2 - Mitigation techniques \\
\hline $\begin{array}{l}\text { WP } 1.3 \text { Near Earth space plasma } \\
\text { modelling and forecasting }\end{array}$ & $\begin{array}{l}\text { WP } 2.3 \text { - Spectrum } \\
\text { management }\end{array}$ & $\begin{array}{l}\text { WP } 3.3 \text { - Scintillation } \\
\text { monitoring and modelling }\end{array}$ \\
\hline $\begin{array}{l}\text { WP } 1.4 \text { - Climate of the upper } \\
\text { atmosphere }\end{array}$ & & \\
\hline
\end{tabular}


- Near Earth space plasma modelling and forecasting including mitigation of ionospheric perturbations, tomographic imaging for model validation and channel modelling techniques.

- Climate of the upper atmosphere including long-term ionospheric trends, gravity and planetary wave effects on propagation and ionospheric space weather.

\subsection{Working Group 2 - \\ Advanced terrestrial systems}

- Radar and radiolocation, including ionospheric effects on surface-wave radar and radiolocation systems, frequency management of ground-wave and sky-wave radars and Angle of arrival measurements for sky-wave signals.

- HF/MF communications including digital radio systems, wideband propagation modelling and development of a hardware simulator, increased capacity of HF links through MIMO techniques (experimental measurements and simulation) and extension of existing wideband HF simulators to the MF band.

- Spectrum management, including the use of GPS to improve HF communications management, adaptive waveform management and the effects of infrasound on radio propagation.

\subsection{Working Group 3 - Space-based systems}

- Ionospheric effects on space-based remote sensing systems, gravity wave effects on GNSS, space plasma media and security implications.

- Mitigation techniques with emphasis on ionospheric structures, their physical nature and impact on GNSS signals, improved accuracy of GNSS by better ionospheric correction and errors due to ionospheric perturbations.

- Scintillation monitoring and modelling with emphasis on scintillation effects, their physical nature and impact on ionospheric radio systems (GNSS signals in particular), high-latitude and equatorial scintillation effects (experimental work and modelling).

\section{COST 296 participating countries and institutions}

\subsection{COST 296 Management Committee}

19 COST member countries signed the COST $296 \mathrm{MoU}$ as shown in table II by names of their representatives. Some 34 active institutions, listed in table III, formed the core of the activity. In addition, institutions from seven non-COST member countries from table IV participated and one observer organization (ESTEC-ESA).

Table II. Members of the COST 296 Management Committee

\begin{tabular}{|c|c|c|}
\hline $\begin{array}{l}\text { R Leitinger, } \\
\text { Insitute for Geophysics, } \\
\text { Astrophysics and Meteorology, } \\
\text { University of Graz, } \\
\text { Universitaetsplatz } \\
\text { A-8010 Graz } \\
\text { W. Riedler } \\
\text { AUSTRIA }\end{array}$ & $\begin{array}{l}\text { R. Warnant, } \\
\text { Observatory of Belgium, } \\
\text { Ave Circulaire 3, } \\
\text { Brussels B-1180, } \\
\text { H.Nebdi } \\
\text { BELGIUM }\end{array}$ & $\begin{array}{l}\text { I. Kutiev, } \\
\text { Geophysical Institute Bulgarian } \\
\text { Academy of Sciences } \\
\text { ‘Acad G Bonchev' Str, Block } 3 \\
1113 \text { Sofia } \\
\text { BULGARIA }\end{array}$ \\
\hline $\begin{array}{l}\text { J. Lastovicka, } \\
\text { Institute of Atmospheric Physics } \\
\text { Academy of Sciences of } \\
\text { Czech Republic } \\
\text { Bocni II cp } 1401 \\
\text { 14131 Praha } 4 \\
\text { J. Boska } \\
\text { CZECH REPUBLIC }\end{array}$ & $\begin{array}{l}\text { E. Turunen, } \\
\text { Geophysical Observatory } \\
\text { Sodankyla } \\
\text { J.P. Luntama } \\
\text { FINLAND }\end{array}$ & $\begin{array}{l}\text { A. Bourdillon, (Chairman) } \\
\text { University of Rennes 1, } \\
35042 \text { Rennes, } \\
\text { Y. Beniguel } \\
\text { FRANCE }\end{array}$ \\
\hline
\end{tabular}


Table II. (continued)

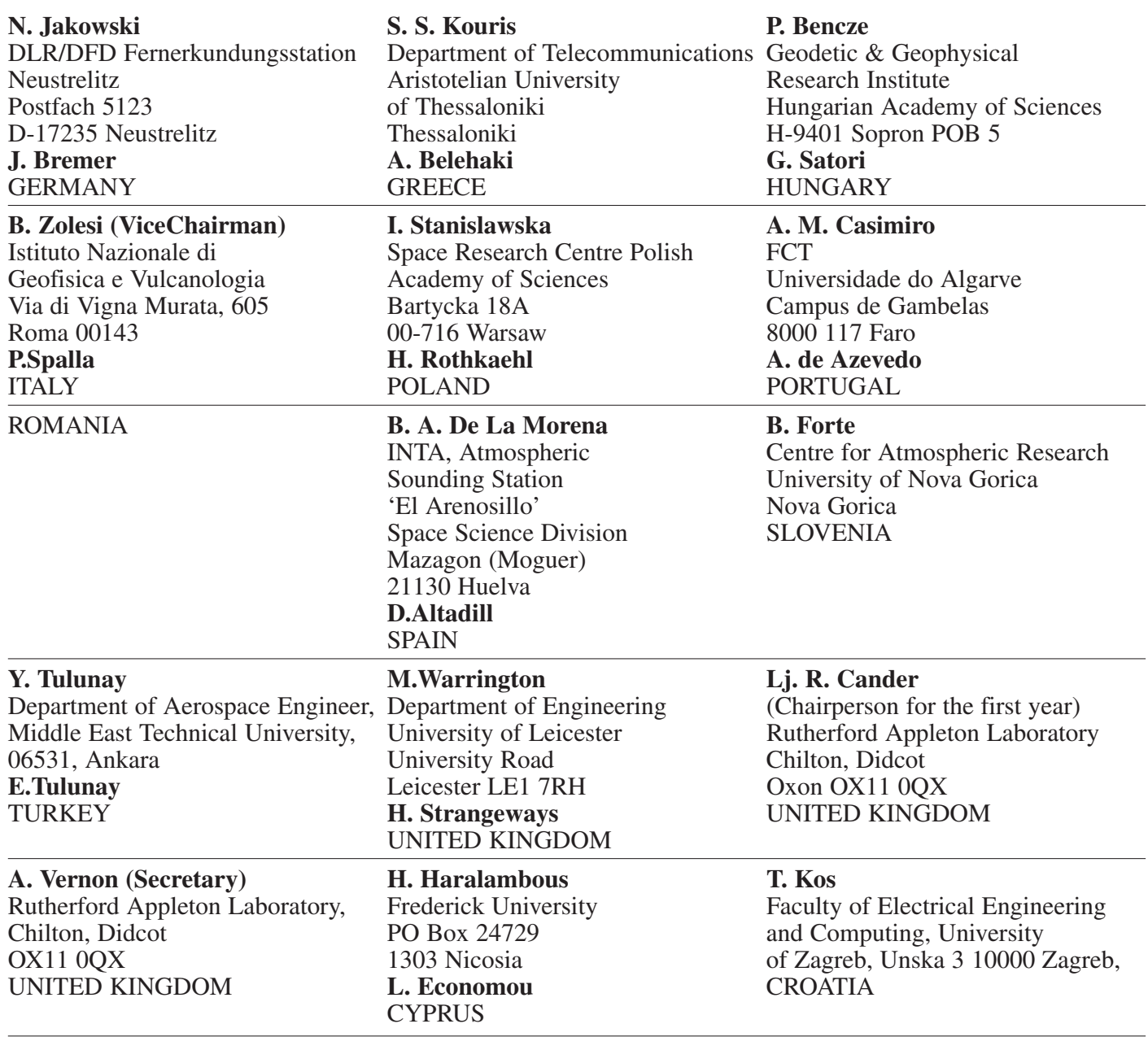

\subsection{Participating Institutions}

Table III. Participating institutions from COST countries

Institute for Geophysics, Astrophysics and Meteorology University of Graz

Geophysical Institute, Bulgarian Academy of Sciences, Bulgaria

Royal Observatory of Belgium, Belgium

University of Liege, Belgium

Institute of Atmospheric Physics, Academy of Sciences of Czech Republic, Czech Republic 
Table III. (continued).

Geophysical Observatory, Sodankyla, Finland

University of Ouly, Finland

Finish Metheorological Institute, Helsinki, Finland

DLR/DFD Fernerkundungsstation, Germany

Leibniz-Institute of Atmospheric Physics, Germany

University of Zagreb, Faculty of Electrical Engineering and Computing, Croatia

IETR, Université de Rennes 1, France

CNRS, Grenoble, France

IEEA, France

Istanbul Technical University (TÜ) Faculty of Aeronautics and Astronautics, Turkey

Middle East Technical University, Ankara, Turkey

INTA, Atmospheric Sounding Station, 'El Arenosillo, Spain

Observatorio del Ebro, Spain

Universidad Complutense Madrid, Madrid, Spain

CEFAT-UCEH, Universidade do Algarve, Portugal

University of Madeira, Portugal

Institut of Geodesy, Warnia and Masuria, Univ. Olsztyn

Space Research Centre, Polish Academy of Sciences, Warsaw, Poland

Istituto Nazionale di Geofisica e Vulcanologia, Italy

Istituto di Fisica Applicata, CNR, Italy

International Center for Theoretical Physics «Abdus Salam», Italy

Department of Telecommunications, Aristotelian University of Thessaloniki, Greece

National Observatory of Athens, Greece

Geodetic \& Geophysical Research Institute, Hungarian Academy of Sciences, Hungary

Rutherford Appleton Laboratory, United Kingdom

QinetiQ, United Kingdom

University of Bath, United Kingdom

University of Wales, United Kingdom

University of Leeds, United Kingdom

University of Leicester, United Kingdom

University of Nottingham, United Kingdom

Sheffield University, United Kingdom

Geomagnetic Institute, Serbia and Montenegro

Frederick University, Nicosia, Cyprus

Intercollege, Limassol, Cyprus 
Table IV. Participating institutions from non- COST countries

Institute of Terrestrial Magnetism, Ionosphere and Radiowave Propagation, Russia

St Petersburg State University, St Petersburg, Russia

University of Massachusetts Lowell, USA

Polar Research Institute of China, Shanghai, China

China Research Institute of Radio Wave Propagation, Beijing, China

Geomagnetic Laboratory, Ottawa, Canada

University Kebangsaan (UKM), Malaysia

\section{MC meetings, workshops, short-term scientific missions}

Table V. Management Committee meetings

4 February 2005, Brussels, Belgium, (Inaugural meeting)

30 May-1 June 2005, Trieste, Italy

13 and 16 November 2005, Noordwijk, Netherlands

27-29 April 2006, Neustrelitz, Germany

3-7 October 2006, Rennes, France

15-17 March 2007, Rome, Italy

10-14 July 2007, Prague, Czech Republic

13-15 March 2008, Limassol, Cyprus

7-11 October 2008, Rome, Italy

20-21 March 2009, Warsaw, Poland (Final meeting)

Table VI. COST 296 Workshops

1st COST 296 Workshop during ESWW2 (2nd European Space Weather Week), Noordwijk, Netherlands, 1418 November 2005, ESTEC.

2nd COST 296 Workshop on «Radio Systems and Ionospheric Effects», Rennes, France, 3-7 October 2006. Papers published on a CD-Rom.

3rd COST 296 Workshop on «Ionosphere, Modelling, Forcing and Telecommunications», 10-14 July 2007, Prague, Czech Republic

4th COST 296 Workshop on «General Review of COST 296 activities and results» 7-11 October 2008, Rome, Italy 
Table VII. COST 296 Meetings of the Working Groups

27 April 2005 Vienna, Austria

4 -5 July 2005, Graz, Austria

27 April 2006, Vienna, Austria

27 April 2007, Vienna, Austria

20-22 February 2008, Nottingham, UK

27 April 2008 Vienna, Austria

4 May 2008

18 November 2008

20 April 2009 Vienna, Austria
W.G. Leaders meeting during the EGU General Assembly

Seminar on ITU-R SG3L issues

W.G. Leaders meeting during the EGU General Assembly

W.G. Leaders meeting during the EGU General Assembly

Ionospheric Scintillation: Scientific aspects, space weather application and services

W.G. Leaders meeting during the EGU General Assembly

W.G. Leaders meeting during the IES, Washington, USA

W.G. Leaders meeting during ESWW5, Brussels, Belgium

W.G. Leaders meeting during the EGU General Assembly

Table VIII. COST 296 Short-term Scientific Missions

Sari M.O. (Middle East Technical University) to E.M. Warrington (University of Leicester), 16-20 January 2006.

Kouba D. (IAP, Prague, CZ) to A. Belehaki (NOA, Athens, Greece) 19-26 March 2006.

Romano V. (INGV Rome, Italy) to A. Bourdillon (University of Rennes, France) 9-16 May 2006.

Krankowski A. (University of Warmia and Mazury, Krakow, Poland) to Manuel Hernandez-Pajares (Technical University of Catalonia, Barcelona, Spain) 25 June-3 July 2006.

Tsagouri I. (NOA, Athens, Greece) to J. Lastovicka (IAP, Prague, CZ) 26 February-3 March 2007.

Gunashekar S. (University of Leicester) to L. Bertel (University of Rennes), 2-6 April 2007.

Kocabas Z. (Middle East Technical University) to L. Bertel (University of Rennes), 2-7 April 2007.

Nechutny Z. (IAP, Prague, CZ) to E. Turunen (Sodankyla Geophysical Observatory, Sondakyla, Finland) 12-23 March 2007.

Hoque M.M. (DLR, Neustrelitz, Germany) to H. Starngeways (University of Leeds, Leeds, UK) 26-30 March 2007.

Fotiadis D. (University of Thessaloiki, Thessaloniki, Greece) to J. Lastovicka (IAP, Prague, CZ) 21-28 April 2007.

Iñigo Blanco Alegre (El Arenosillo, INTA) carried out a Short-Term mission (STM) at the INGV, Instituto Nazionale di Geofisica e Vulcanologia in Rome in September 10-17, 2007.

Bidaine B. (FNRS Belgium) to S. Radicella (ICTP, Trieste, Italy) 10-21 December 2007.

Tsagouri I. (NOA, Athens, Greece) to B. Zolesi (INGV, Instituto Nazionale di Geofisica e Vulcanologia in Rome) May 26-30, 2008.

Kouris S. (University of Thessaloniki, Thessaloniki, Greece) to I. Stanilawska (SRC, Warsaw, Poland) 25-30 May 2008.

Rothkhael H. (SRC Warsaw, Poland) to E.M. Warrington (University of Leicester, Leicester, UK) 19-24 May 2008.

Mielich J. (IAP, University of Rostock, Juliusruh, Germany) to Lj. Cander (Rutherford Appleton Laboratory, Didcot, UK) 19-24 May 2008.

Yapici T. and Tulunay E. (Middle East Technical University) to S. Radicella (ITCP, Trieste, Italy) 22-27 June 2008. 


\section{Dissemination of results}

The target audiences for the dissemination of the COST 296 Action results include other scientists, researches and engineers working in the field; other research frameworks and international organization; institutes and academia; standards bodies; industry; European level policy makers; government policy makers, regional planners and policy makers; general public.

The dissemination methods used in the course of the COST 296 Action have been: (1) posting of general information and working documents on the COST 296 website including set up of an electronic communication network; (2) Workshops, seminars, events, schools for young scientist and conferences organised by the MC including contributions to other national and international conferences and symposia; (3) Online Proceedings, CD Proceedings and papers in peer-reviewed related scientific and technical Journals. Dissemination of results took into consideration the progress of the COST 296 Action as well the results of its evaluation in updating the dissemination plan during the course of this Action.

\subsection{COST 296 Action Website}

The Website of the COST 296 Action has been active since the beginning of the action on the following address:

\section{http://www.cost271.rl.ac.uk/.}

It is maintained at Rutherford Appleton Laboratory, UK and contains the COST 296 Action main info documents as the management structure, the Minutes of the Management Committee meetings, the Call for papers and other relevant documents for the action in addition to the related web links.

\subsection{Major Events organized/co-organized by MC}

1. The 2nd General Assembly of the EGU 2005 Session related to COST 296 Action on «Ionospheric monitoring and modelling for ad- vanced terrestrial and space-based systems», 24-29 April 2005, Vienna, Austria.

2. The 2nd European Space Weather Week (joint Workshop COST 296, COST 724, ESA and E-STAR); 14-18th November 2005, ESAESTEC, Noordwijk, Netherlands.

3. The 3rd General Assembly of the EGU 2006 Session related to COST 296 Action on «Measurements of ionospheric parameters influencing radio systems», 2-April 2006, Vienna, Austria.

4. International Advanced School on Space Weather at ICTP (joint activity with COST 724), 2-19 May 2006, ICTP, Trieste, Italy.

5. 2nd COST 296 Workshop «Radio Systems and Ionospheric Effects», University of Rennes 1, 3-7 October 2006, Rennes, France.

6. The 4th General Assembly of the EGU 2007 Session related to COST 296 Action on «Modelling and measurements of ionospheric parameters influencing radio systems» and Working Group leaders meeting, 15-20 April 2007, Vienna, Austria.

7. Joint COST 296 and International Reference Ionosphere Workshop on «Ionosphere Modelling, Forcing, and Telecommunications», 10-14 July 2007, Prague, Czech Republic.

8. COST 296 Workshop on «Ionospheric Scintillation: Scientific aspects, Space Weather application and Services 'Workshop on Ionospheric Scintillations, Measurements and Modelling'», 20-22 February 2008, Nottingham University, Nottingham, UK.

9. International School of Space Science, Geomagnetism and Ionosphere School, 7-12 April 2008, L'Aquila, Italy.

10. The General Assembly of the EGU 2008 Session related to COST 296 Action on «Studies of ionospheric parameters influencing radio systems» and Working Group leaders meeting, 13-18 April 2008, Vienna, Austria. 
11. The International Ionospheric Effects Symposium Session related to Results derived from COST-ACTION programs «Mitigation of Ionospheric and Space Weather Effects on Telecommunication and Navigation», 13-15 May 2008, City of Alexandria, USA.

12. The 4th Workshop of the COST 296 Action Mitigation of Ionospheric Effects on Radio Systems (MIERS), 7-11 October 2008, INGV, Rome, Italy.

13. The 5th European Space Weather Week (jointly organised by the Royal Observatory of Belgium (ROB), ESA, the SWWT, the COST 724 and COST 296 communities); 16-21 November 2008, Brussels, Belgium.

14. COST 296 Action Final Meeting, Warsaw, 20-21 March 2009.

15. The General Assembly of the EGU 2009 Session ST11 related to COST 296 Action on «Ionosphere and radio systems» and Working Group leaders meeting, 19-24 April 2009, Vienna, Austria.

\subsection{Major Publications}

Most of the results reporting activities of the COST 296 Action have been published as follows:

1. Online Proceeding and Space Weather Book from the 2nd European Space Weather Week, 14-18th November 2005, ESA-ESTEC, Noordwijk, The Netherland.

2. 2nd COST 296 Workshop CD Proceedings on «Radio Systems and Ionospheric Effects», University of Rennes 1, Rennes, France, 3-7 October 2006.

3. Special volume of Acta Geophysica devoted to the selected papers from the 3rd General Assembly of the EGU 2006 Session related to COST 296 Action on «Measurements of ionospheric parameters influencing radio systems», Vol. 55, No. 3, 2007.
4. Special volume of Journal of Atmospheric and Solar-Terrestrial Physics devoted to the selected papers from the 3rd General Assembly of the EGU 2006 Session related to COST 296 Action on «Measurements of ionospheric parameters influencing radio systems», Vol. 70, Issue 6, April 2008, doi: 10.1016/j.jastp.2007.02.016.

5. Online Proceedings of the COST 296 Workshop on «Ionospheric Scintillation: Scientific aspects, Space Weather application and Services 'Workshop on Ionospheric Scintillations, Measurements and Modelling'», 20-22 February 2008, Nottingham University, Nottingham, UK.

6. Special volume of Journal of Atmospheric and Solar-Terrestrial Physics devoted to the selected papers from the 4th General Assembly of the EGU 2007 Session related to COST 296 Action on «Modelling and measurements of ionospheric parameters influencing radio systems», Vol. 70, Issue 15, December 2008, doi:10.1016/j.jastp.2008.01.016.

7. Special volume of Advances in Space Research devoted to the selected papers from the joint COST 296 and International Reference Ionosphere Workshop on «Ionosphere - Modelling, Forcing, and Telecommunications», in press 2008.

8. COST 296 Final Report; Supplement to Annals of Geophysics, 2009, this issue.

\section{Scientific and technical cooperation}

The close scientific collaborations established as part of previous COST 238, 251 and 271 actions have led to a number of bilateral and multilateral collaborations successfully continued in the COST 296 Action.

In addition, participants of this action have been active in different European projects. There is a significant participation of Action members from all Working Groups in ESA Space Weather Program, in particular in its Space Weather Working Team (SWWT), the SWENET (Space Weath- 
er European Network) scheme (http://www.esaspaceweather.net/swenet) and SWEETS (the main space weather festival during the European Science Week 19-24 November 2007) at the Schwerin castle/House of Parliament in Germany).

Particularly important has been the collaboration between two COST actions: COST 724 devoted to space weather and COST 296 devoted to the study of the ionosphere and its impact on communication and positioning. Several colleagues work in the two actions. This resulted is an important input provided by the COST 296 action to COST 724 based on the ionospheric models developed during the last COST actions (COST 238, 251, 271 and 296) for space weather applications (see Lilensten et al., 2007 for details).

The URSI Beacon Satellite Group closely linked to the work of the Working Group 3 of this action, provides important links between ionosphere, plasmasphere and upper atmosphere scientists, engineers and users of satellite beacon applications. Several COST 296 Group members are advisers and observers in the International Geodynamics Service (IGS) and some of its offspring organisations like the GPS-IONO group.

Designed to meet the needs of Europe, this action also made an impact to the international work of ITU-R Study Group 3L through contributions to Recommendations, provision of data for validation of prediction models for Europe and by a leading role in Working Party SG3L (Ionospheric Propagation).

Further steps will be taken to make the most applicable results of the COST 296 results available to ITU-R.

Moreover participants in this action have made a considerable contribution to the International Heliophysical Year (2007-2009) initiatives with the following activities: (a) Development and maintenance of COST 296/IHY web site to exchange general information, expertise, know-how, links to the data archive and databases produced by this Action among the IHY community (see http://ionos.ingv.it/IHY/ihy_index.html.); (b) Coordination of multi-instruments observation campaigns in synergy with the IHY community.
The data archive created during the observation periods and/or severe heliogeophysical conditions will also form a baseline collection against which later forecasting efforts may be compared; (c) Joint investigations on interconnection between low, middle and high latitude ionosphere and plasmasphere, e.g. PGHM campaign (see http://www.bu.edu/cawses).

Finally, it should be mentioned other international activities of the Ionospheric COST community by the organization of the session «Mitigation of Ionospheric and Space Weather Effects on Telecommunication and Navigation» during the International Ionospheric Effects Symposium, in Alexandria, USA, May 2008 and a long-lasting collaboration with the International Reference Ionosphere (IRI) by organizing the combined IRI/COST 296 workshop strongly oriented towards application of ionospheric models and specifically on their effects on radio systems.

\section{Outline of the final report}

The COST 296 Final Report is published here as a supplement of the international journal Annals of Geophysics.

It comprises this Introduction that contains the COST 296 Action background and historical context, the general objectives and priorities agreed in the Memorandum of Understanding, the working methods and structure, the participating countries and institutions, information about the MC meetings, workshops and short-term scientific missions, dissemination of results and finally the scientific and technical cooperation. Ten scientific papers concerning the main activities and results achieved in the three Working Groups of COST 296 follow. Each paper is in the form of an independent review of one of the activities of the Action with an introduction, discussion of the results and references. Two scientific papers, in which group of authors review the main achievements obtained in ionospheric COST related actions, make up the final part of this report.

The Conclusions summarises the main achievements of COST 296 as a whole in the 
context of the MoU requirements and looks to the way ahead. Significant achievements have been made, developing our understanding of the issues and relevance of field and offering new knowledge that will serve to increase economic and social development. In addition, new challenges have been identified and a concrete proposal is outlined for follow-on from COST 296.

The COST 296 Final Report is addressed mainly to those in the MoU signatory countries involved in frequency planning, spectrum management and system design; to those who sponsored the work undertaken; to industrial partners concerned with the technology who will learn from the results and to those in national radio regulatory administrations and international planning. In addition, the report is of interest to students of radiowave communication and navigation and others in the propagation research community.

\section{REFERENCES}

BRADLEY, P.A. (1995): PRIME (Prediction Regional Ionospheric Modelling over Europe), COST Action $238 \mathrm{Fi}$ nal Report, (Commission of the European Communities, Brussels).

HANBABA, R. (1999): Improved Quality of Service in Ionospheric Telecommunication Systems Planning and Operation, COST Action 251 Final Report, (Space Research Centre, Warsaw).

Lilensten, J., B. Zolesi, A. Belehaki, I. Stanislawska, and L. PERrone (2007): Collaboration among COST actions. Ionosphere and space weather, COST $724 \mathrm{Fi}$ nal Report.

Zolesi, B., and Lu. R. CANDER (2004): COST 271 Action «Effects of the upper atmosphere on terrestrial and Earth-space communications» Final Report, Annals of Geophysics, supp. 47 (2/3).

Zolesi, B. and LJ. R. CANDER (2008): «From COST 238 to COST 296: Four European COST. Actions on Ionospheric Physics and Radio Propagation», Radio Sounding and Plasma Physics: 2007 Radio Plasma Imager Science Team Meeting, April 27, 2007, Radio Sounding and Plasma Physics Symposium, April 29, 2007, XI International Digisonde Forum, April 30 May 3, 2007, AIP Conference Proceedings, Vol. 974, pp. 39-46. 